\title{
The making of medical ethics
}

When the first issue of this journal was published in April 1975 its inaugural editorial stated:

\section{The aim of the Journal of Medical Ethics is to provide a forum for the rea- soned discussion of moral issues arising from the provision of medical care. It will hold no brief for one particular pro- fessional, political, or religious view- point. The articles it publishes will identify current problems, present factual information, and clarify different moral assumptions. To fulfil these aims the Editors can call on the resources of the disciplines of law, philosophy, and theology, as well as on the whole range of medical and paramedical specialties. ${ }^{1}$}

This prospectus well expressed the ethos of the journal's original publisher, the Society for the Study of Medical Ethics (SSME), and was clearly reflected in the content and style of the journal's early issues. It was also reflected in the journal's authorship, which included many leading medical and other academics and professionals of the time, who demonstrated lively engagement with a variety of emerging moral issues. In due course such issues would be well recognised as the substance of 'medical ethics', but in 1975, as the editorial also noted, that 'phrase' could still 'create misunderstandings and provoke suspicions (especially perhaps among medical readers)'. ${ }^{1}$ Hence the need for the clear prospectus.

Further reflections on the origins and development of the journal are provided in a paper co-authored by all of its editors since 1975 (see page 667), but a no less significant focus of the papers in the first section of this issue is on the circumstances which made publication of the journal possible. The SSME was a postgraduate association which grew out of student medical groups, eventually established in all British medical schools, for the study and discussion of 'issues raised by the practice of medicine which concern other disciplines'. The original, largest, and most influential of these was the London Medical Group (LMG), which held its first lecture series in 1963: reflections on its origins, development, and legacy are provided in a paper by the founder of the LMG, Edward
Shotter, and others involved at the time (see page 662).

Fifty years on, the legacy of the LMG is now being carried forward by the Institute of Medical Ethics (IME), successor to the SSME, whose current chair and general secretary address its vision for the future in a further paper in the first section of this issue (see page 669). The remaining paper in this section, by Brian Hurwitz (see page 672), discusses the history and rationale of 'one of the most polymorphous, adventurous and lively heirs' of the LMG, the field of study now familiarly known as 'medical humanities' and well represented in our sister journal of that name. The relationship between medical ethics and medical humanities has been both cordial and productive, and even personal-a leading initiator of the 'Windsor Declaration' mentioned by Hurwitz, was the most recent Honorary President of the IME, Sir Kenneth Calman, contributor of several significant papers to this journal and sometime co-founder of the Glasgow Medical Group.

How far do the remaining papers in this issue of the journal reflect the priorities of its original prospectus? Four broad themes were addressed in the April 1975 issue: ethics and the professions; euthanasia and palliative care; research ethics committees; and donor insemination. Aspects of the first of these are examined in the current issue in papers on medical confidentiality and the competent patient (see page 686), patient consent for student involvement in pelvic examination (see page 676), and conscientious objection by Muslim students (see page 708). Aspects of euthanasia and palliative care are discussed in papers on attitudes to euthanasia and physician assisted suicide (see page 713), and on the ethics of imperfect cures (see page 690). Aspects of the work of research ethics committees are included in papers on evolving standards (see page 699), and on the placebo effect in sham-controlled trials (see page 703, Editor's choice), while papers on the use of animals (see page 717) and on evaluation of clinical ethics support services (see page 681) might also fit an updated version of this category.
Donor insemination is not discussed in the current issue, but the possible implications of such advances in reproductive medicine, barely on the horizon in 1975, now include that of radical human enhancement, examined in a paper in this issue about creating beings with moral standing superior to our own (see page 709). Some aspects of that currently controversial topic, moreover, relate to an ethical analysis of the concept of determinism in the journal's first issue, which also included a case conference on abortion and sterilisation, aspects of the latter being the subject of a paper in the current issue on tubal sterilisation (see page 710).

While continuity in many of the broad themes addressed over the years can be demonstrated, the repeated reference above to various 'aspects' of those themes indicates how much more detailed, and often deeper, has become the examination of current issues in medical ethics. The danger in this, of course, is that medical ethics might become an isolated, 'remote and ineffectual', academic discipline of no interest or assistance to clinicians-the 'suspicions (especially perhaps among medical readers)' alluded to in the original prospectus. This fate, we believe, has not befallen the Journal of Medical Ethics. The moral questions subject to 'reasoned discussion' in the current and recent issues are of considerable relevance to clinicians and patients as well as to ethicists; and the academic disciplines and medical specialties mentioned in the journal's prospectus continue to be wellrepresented among its contributors. These also continue to be international: in the first issue most contributors were from the UK, with some also from Europe and North America-to all of whom the current issue adds contributors from Australia, New Zealand, India and Brazil. Fifty years on from the founding of the LMG, its spirit appears to be alive, well, and worldwide.

\section{Competing interests None.}

Provenance and peer review Commissioned; internally peer reviewed.

\section{REFERENCE}

1 Campbell AV. Editorial. J Med Ethics 1975;1:1. 